\title{
A Comparative EPR Study of Non-Substituted and Mg-Substituted Hydroxyapatite Behaviour in Model Media and during Accelerated Ageing
}

\author{
Monica Vidotto ${ }^{1,+}$, Timor Grego ${ }^{2,3,+}$, Božana Petrović ${ }^{4}\left(\mathbb{D}\right.$, Nicolas Somers ${ }^{5}$ (D) Tatjana Antonić Jelić 6 (D), \\ Damir Kralj ${ }^{7}$, Nives Matijaković Mlinarić ${ }^{7}(\mathbb{D})$, Anne Leriche ${ }^{5}$, Maja Dutour Sikirić ${ }^{8}$, Ina Erceg ${ }^{8, *}$ \\ and Nadica Maltar-Strmečki ${ }^{1, * \mathbb{D}}$
}

check for updates

Citation: Vidotto, M.; Grego, T.; Petrović, B.; Somers, N.; Antonić Jelić, T.; Kralj, D.; Matijaković Mlinarić, N.; Leriche, A.; Dutour Sikirić, M.; Erceg, I.; et al. A Comparative EPR Study of Non-Substituted and Mg-Substituted Hydroxyapatite Behaviour in Model Media and during Accelerated Ageing. Crystals 2022, 12, 297. https://doi.org/10.3390/ cryst12020297

Academic Editor: Jaime Gómez Morales

Received: 3 February 2022 Accepted: 18 February 2022 Published: 19 February 2022

Publisher's Note: MDPI stays neutral with regard to jurisdictional claims in published maps and institutional affiliations.

Copyright: (C) 2022 by the authors. Licensee MDPI, Basel, Switzerland. This article is an open access article distributed under the terms and conditions of the Creative Commons Attribution (CC BY) license (https:// creativecommons.org/licenses/by/ $4.0 /)$.
1 Laboratory for Electron Spin Spectroscopy, Division of Physical Chemistry, Ruđer Bošković Institute, Bijenička c. 54, 10000 Zagreb, Croatia; monica.vidotto@irb.hr

2 Department of Occupational Safety and Health, Fire and Radiation Protection Ruđer Bošković Institute, Bijenička c. 54, 10000 Zagreb, Croatia; timor.grego@irb.hr

3 Department of Urology, University Hospital Centre Zagreb, Kispaticeva 12, 10000 Zagreb, Croatia

4 Laboratory for Atomic Physics, Vinča Institute of Nuclear Sciences-National Institute of the Republic of Serbia, Belgrade University, Mike Petrovića Alasa 12-14, Vinča, 11351 Belgrade, Serbia; bozana@vin.bg.ac.rs

5 FR CERAMATHS Département Matériaux et Procédés, Université Polytechnique Hauts-de-France (UPHF), 59600 Maubeuge, France; nicolas.somers@uphf.fr (N.S.); anne.leriche@uphf.fr (A.L.)

6 Laboratory for Synthesis of New Materials, Division of Materials Chemistry, Ruđer Bošković Institute, Bijenička c. 54, 10000 Zagreb, Croatia; tatjana.antonic.jelic@irb.hr

7 Laboratory for Precipitation Processes, Division of Materials Chemistry, Ruđer Bošković Institute, Bijenička c. 54, 10000 Zagreb, Croatia; damir.kralj@irb.hr (D.K.); nives.matijakovic.mlinaric@irb.hr (N.M.M.)

8 Laboratory for Biocolloids and Surface Chemistry, Division of Physical Chemistry, Ruđer Bošković Institute, Bijenička c. 54, 10000 Zagreb, Croatia; sikiric@irb.hr

* Correspondence: ierceg@irb.hr (I.E.); nstrm@irb.hr (N.M.-S.)

+ These authors contributed equally to this work.

Abstract: To assess the application potential of novel biomaterials, their behaviour in model media and upon sterilization should be investigated, as well as the stability related to their storage conditions. Such data are lacking for Mg-substituted HAP (Mg-HAP). Therefore, the changes in the local structure of non-substituted and Mg-HAP after irradiation and immersion in corrected simulated fluid and saline solution for 28 days were followed by electron paramagnetic resonance (EPR) spectroscopy for the first time. To better understand the stability of radical species induced by sterilization, EPR spectra of samples kept for $2 \mathrm{~h}$ at temperatures up to $373 \mathrm{~K}$ were recorded to provide an insight into the stability of the sample storage conditions by the accelerated aging method. Samples were characterized by PXRD, FTIR, SEM, EDS, AAS and TGA. Results confirmed that irradiation does not induce changes in the composition or the structure of any of the investigated materials. Fading or the complete disappearance of radical signals in the EPR spectra after immersion in both media was accompanied by the disappearance of other phases formed as a minor byproduct in the synthesis of substituted HAP, as confirmed by PXRD and FTIR analysis. Obtained results confirm the great potential of Mg-HAPs for biomedical applications, although closer attention should be given to the processes related to sample storage stability at different temperatures.

Keywords: ion-substituted hydroxyapatite; magnesium; electron paramagnetic spectroscopy; simulated body fluid; saline

\section{Introduction}

Hydroxyapatite $\left(\mathrm{HAP}, \mathrm{Ca}_{10}\left(\mathrm{PO}_{4}\right)_{6}(\mathrm{OH})_{2}\right)$ is the thermodynamically most stable calcium phosphate $(\mathrm{CaP})$ phase and is often considered the most similar among different CaPs to the mineral component of vertebrate's hard tissues [1]. In addition, HAP has excellent cytocompatibility and osteoconductivity, making it one of the most investigated 
materials in bone tissue engineering [2-4]. However, the mineral component of hard tissues, so-called biological apatite, is non-stoichiometric, poorly crystalline, ion-substituted hydroxyapatite $[1,2,5]$. Due to the specific biological roles that substitute ions have in bone metabolism, introducing substitute ions into HAP structure attracts increased attention as a way of increasing its bioactivity [2,6-9]. The crystal structure of stoichiometric HAP allows for several different anions and cations to be used as substitutions [6,7]. Although two HAP polymorphs are known, hexagonal and monoclinic, the monoclinic form is unstable even when a small amount of foreign ions are present and, therefore, in general, it is not found in biological apatites [7]. HAP's unit cell contains 10 calcium ions, 6 phosphate ions and two $\mathrm{OH}^{-}$groups $[6,10]$. In the hexagonal form two different cation sites $(\mathrm{Ca}(\mathrm{I})$ and $\mathrm{Ca}(\mathrm{II}))$ are present, as well as one independent phosphate site. Small cations in addition to small amounts of larger cations can be accommodated at the $\mathrm{Ca}(\mathrm{I})$ site, while large cations can be accommodated at the $\mathrm{Ca}(\mathrm{II})$ site. Anions like $\mathrm{F}^{-}$and $\mathrm{Cl}^{-}$can substitute $\mathrm{OH}^{-}$or $\mathrm{PO}_{4}^{3-}$ positions, while $\mathrm{CO}_{3}^{2-}$ can be accommodated at both sites [7]. Since the ions of different valences can be used as substitutions, to maintain electroneutrality, the positions of $\mathrm{OH}^{-}$ groups can be left vacant $[7,10]$. In biological apatites, $\mathrm{Ca}^{+}$ions can be substituted with $\mathrm{Na}^{+}, \mathrm{K}^{+}, \mathrm{Mg}^{2+}, \mathrm{Sr}^{2+}, \mathrm{PO}_{4}^{3-}$ or $\mathrm{HPO}_{4}^{2-}$ ions with $\mathrm{CO}_{3}^{2-}$ and $\mathrm{OH}^{-}$ions can be substituted with $\mathrm{F}^{-}, \mathrm{Cl}^{-}, \mathrm{CO}_{3}^{2-}$ [6]. Among the different possible substitute ions, $\mathrm{Mg}^{2+}$ attracts special attention as it is an important trace element in bone and teeth [1,11,12]. It plays a key role in bone metabolism since it influences osteoblast and osteoclast activity, and thereby bone growth. Moreover, a lack of magnesium is associated with decreased osteoblast activity, bone fragility, and osteoporosis [2,13-15]. Simultaneously, it is beneficial in processes like cell proliferation and differentiation, as well as osteoconductivity and resorption [2].

The majority of the investigations of Mg-substituted HAPs (as well as other ionsubstituted HAPs) are focused on developing efficient preparation techniques, determining the maximum amount of substitution that can be achieved, as well as determining the effect that certain ions or a combination can have on the structure and biological behaviour of ion-substituted apatites $[6,7,16,17]$. Only recently, the behaviour of ion-substituted apatites in media relevant for their application started to intrigue experts from various fields. For example, Andrés et al. showed that the degradation rate of Mg substituted HAP in PBS, PBS with lysozyme, and acetate buffer increases with increasing Mg content [18]. The surface of multi-substituted HAP nanoparticles (Mg, Zn, Sr, Si-HAP and Mg, Zn, Si-HAP) was shown to be more susceptible to dissolution in SBF (simulated body fluid) and water due to the lattice strain provoked by the simultaneous multi-substitution of ions in the structure of HAP [19]. However, to date, no data on the changes in the local structure of Mg-substituted HAP during exposure to different media has been published.

Moreover, the characterisation of ion-substituted HAPs after sterilization and during storage is necessary to get a better overview of the effect of different substitutes, as well as the sterilization procedure and storage conditions on their physical-chemical properties. Currently, the most efficient sterilization method for the inactivation of bacteria and microorganisms in biomaterials is gamma irradiation, due to its high penetrating ability, uniformity, and time-dependent delivery of the required doses which increases product safety [20].

However, the current literature provides different information about the effects of the different irradiation on the formation and stability of the free radicals in the bone graft materials during and after the sterilization procedure [21,22]. Accordingly, the post radiation behaviour is highly dependent on the structure of the bone grafts and their constituents, especially additives like polymers, and it also depends on the different type of radiation and dose value applied, therefore further investigations are needed [23-26]. On the other hand, gamma radiation induces defects or free radicals in the material with a different nature and structure, which depend on the composition and the synthesis conditions of the samples. In addition, they can present different behaviour in physiological solutions [19]. Furthermore, due to the importance of the shelf-life of the material for biomedical applications and storage conditions, the accelerated ageing method is used. The 
primary reason for using accelerated-aging techniques in the quality testing of a materials is to bring the product to market at the earliest possible time. The aging of materials refers to the variation of their properties over time, the properties of interest being those related to safety and efficacy. Accelerated product aging can be defined as a procedure that seeks to determine the reaction of a material under normal-usage conditions over a relatively long time, by exposing the product to stresses for a much shorter time, i.e., higher temperatures are more frequently or more severely applied than normal environmental or operational stresses [27]. Such investigations are scarce in the literature.

In order to fill this void, EPR (electron paramagnetic resonance) spectra of $\mathrm{Mg}$ substituted hydroxyapatite (Mg-HAP) and non-substituted HAP (HAP) sterilized by gamma irradiation, before and during immersion in corrected simulated body fluid (c-SBF) and saline solution (SS), were acquired and analysed. In addition, the changes during accelerated ageing were also followed. EPR spectroscopy was chosen since it is the established method for the detection and identification of free radicals and defects, no matter the crystalline state, with high sensitivity which can reach up to one detected defect out of $10^{7}$ molecules. Further advantages are non-invasive measurement and the possibility to monitor samples for a long time without any influence on the stability [28]. Compared to other methods, EPR spectroscopy can give insight into the microstructure and changes of the local environment in the lattice of HAP induced by different substitutes and the sterilization procedure. It can also detect the changes during immersion in different media, that mimic physiological conditions, or during storage.

\section{Materials and Methods}

\subsection{Materials}

Analytical grade chemicals calcium chloride $\left(\mathrm{CaCl}_{2}\right)$, sodium hydrogenphosphate $\left(\mathrm{Na}_{2} \mathrm{HPO}_{4}\right)$, sodium chloride $(\mathrm{NaCl})$, sodium hydrogencarbonate $\left(\mathrm{NaHCO}_{3}\right)$, potassium chloride $(\mathrm{KCl})$, di-potassium hydrogen phosphate trihydrate $\left(\mathrm{K}_{2} \mathrm{HPO}_{4} \cdot 3 \mathrm{H}_{2} \mathrm{O}\right)$, magnesium chloride hexahydrate $\left(\mathrm{MgCl}_{2} \cdot 6 \mathrm{H}_{2} \mathrm{O}\right)$, sodium sulfate $\left(\mathrm{Na}_{2} \mathrm{SO}_{4}\right)$, Tris-hydroxymethyl aminomethane $\left(\left(\mathrm{HOCH}_{2}\right)_{3} \mathrm{CNH}_{2}\right.$, Tris), hydrochloric acid $(\mathrm{HCl})$, sodium hydroxide $(\mathrm{NaOH})$, calcium nitrate tetrahydrate $\left(\mathrm{Ca}\left(\mathrm{NO}_{3}\right)_{2} \cdot 4 \mathrm{H}_{2} \mathrm{O}\right)$ and magnesium nitrate $\left(\mathrm{Ca}\left(\mathrm{NO}_{3}\right)_{2} \cdot 4 \mathrm{H}_{2} \mathrm{O}\right)$ were obtained from Sigma Aldrich (Steinheim am Albuch, Germany). Saline solution Ultrapure water (UPW) was used in all experiments. Di-ammonium phosphate $\left(\left(\mathrm{NH}_{4}\right)_{2} \mathrm{HPO}_{4}\right)$ was purchased from Carlo Erba (Val de Reuil, Normandie, France), while calcium nitrate $\left(\mathrm{Ca}\left(\mathrm{NO}_{3}\right)_{2}\right)$ was purchased from Brenntag (Chassieu, Auvergne-Rhône-Alpes, France). The saline solution used in this study was a $0.9 \% \mathrm{NaCl}$ solution by B. Braun (Rottweil, Germany).

\subsection{Synthesis of Non-Substituted Hydroxyapatite and Mg-Substituted Hydroxyapatite}

Hydroxyapatite was synthesised according to the procedure described by Chamary et al. [29]. For that purpose, a di-ammonium phosphate solution $\left(\mathrm{NH}_{4}\right)_{2} \mathrm{HPO}_{4}$ was added in a controlled manner to a calcium nitrate solution $\mathrm{Ca}\left(\mathrm{NO}_{3}\right)_{2}$, in a jacketed reactor under mechanical stirring. An ammonia solution maintained the alkaline $(\mathrm{pH} 8)$ conditions needed in the reactor. The reaction (Equation (1)) took place at $50{ }^{\circ} \mathrm{C}$ for $20 \mathrm{~h}$. The solution was then filtered, and the solid matter was dried at $90^{\circ} \mathrm{C}$ for $48 \mathrm{~h}$.

$10 \mathrm{Ca}\left(\mathrm{NO}_{3}\right)_{2}(\mathrm{aq})+6\left(\mathrm{NH}_{4}\right)_{2} \mathrm{HPO}_{4}(\mathrm{aq})+8 \mathrm{NH}_{4} \mathrm{OH}(\mathrm{aq}) \rightarrow \mathrm{Ca}_{10}\left(\mathrm{PO}_{4}\right)_{6}(\mathrm{OH})_{2}(\mathrm{~s})+20 \mathrm{NH}_{4} \mathrm{NO}_{3}(\mathrm{aq})+6 \mathrm{H}_{2} \mathrm{O}$

For the synthesis of Mg-substituted HAP, $100 \mathrm{~mL}$ of $\left(\mathrm{NH}_{4}\right)_{2} \mathrm{HPO}_{4}$ solution ( $\mathrm{c}=0.299 \mathrm{~mol} \mathrm{dm}^{-3}$ ) was added in a controlled manner to $200 \mathrm{~mL}$ of solution containing $\mathrm{Ca}\left(\mathrm{NO}_{3}\right)_{2} \cdot 4 \mathrm{H}_{2} \mathrm{O}\left(\mathrm{c}=0.244 \mathrm{~mol} \mathrm{dm}^{-3}\right)$ and $\mathrm{Mg}\left(\mathrm{NO}_{3}\right)_{2} \cdot 6 \mathrm{H}_{2} \mathrm{O}\left(\mathrm{c}=0.006 \mathrm{~mol} \mathrm{dm}^{-3}\right)$. The reaction mixture was heated under reflux at $100{ }^{\circ} \mathrm{C}$ for $5 \mathrm{~h}$. During heating, urea and urease were added and a $\mathrm{pH}$ of 8.8 was obtained. The product was filtered, washed with MilliQ water and ethanol, and dried at $120^{\circ} \mathrm{C}$ for $24 \mathrm{~h}$. 


\subsection{Immersion in Corrected Simulated Body Fluid (c-SBF) and Saline Solution (SS)}

c-SBF and SS were chosen as the model media for saliva and human blood plasma, respectively.

Corrected simulated body fluid was prepared using the procedure described by Kokubo and Takadama [30]. As prepared c-SBF contains $142 \mathrm{mM} \mathrm{Na}^{+}, 5 \mathrm{mM} \mathrm{K}^{+}, 1.5 \mathrm{mM}$ $\mathrm{Mg}^{2+}, 2.5 \mathrm{mM} \mathrm{Ca}^{2+}, 147.8 \mathrm{mM} \mathrm{Cl}^{-}, 4.2 \mathrm{mM} \mathrm{HCO}_{3}^{-}, 1.0 \mathrm{mM} \mathrm{HPO}_{4}^{2-}$ and $0.5 \mathrm{mM} \mathrm{SO}_{4}^{2-}$, $10 \mathrm{mg}$ of HAP and Mg-substituted HAP were added in $2 \mathrm{~mL}$ Eppendorf tubes along with 1 $\mathrm{mL}$ c-SBF. The tubes were kept in a thermostated water bath at $37^{\circ} \mathrm{C}$ for 28 days. The c-SBF was exchanged every day by centrifugation and decantation. The solid phase was filtered on the 1st, 14th, and 28th day through $0.45 \mu \mathrm{m}$ Millipore filter paper, washed 3 times with MilliQ water, one time with ethanol, and dried in nitrogen gas flow. The samples were kept in a desiccator until further analysis.

\subsection{Sample Irradiation}

All samples were irradiated in the presence of air at room temperature by using gamma rays from the panoramic Co-60 irradiator in the Radiation Chemistry and Dosimetry Laboratory at the Ruđer Bošković Institute. The total dose was 25 kGy. Dose mapping of the irradiation facility has been performed experimentally (using ionizing chambers and an ECB dosimetric system) and by simulation calculations [31].

\subsection{Characterization Methods}

\subsubsection{Powder X-ray Diffraction (PXRD)}

PXRD patterns were recorded on Panalytical Aeris Research Edition (Malvern Panalytical, Malvern, UK) in Bragg-Brentano geometry using $\mathrm{CuK} \alpha$ radiation in an angular scan range from $5^{\circ}$ to $70^{\circ} 2 \theta$ using a step size of $0.02^{\circ} 2 \theta$ and a scan rate of $1^{\circ} \mathrm{min}^{-1}$.

\subsubsection{Fourier Transform Infrared Spectroscopy (FTIR)}

FTIR spectra of the samples were recorded on a Tensor I, Bruker, FTIR spectrometer equipped with an attenuated total reflection module (Ettlingen, Germany) in the range from $4000 \mathrm{~cm}^{-1}$ to $400 \mathrm{~cm}^{-1}$, with a resolution of $1 \mathrm{~cm}^{-1}$. The presented spectra are the average of 16 scans.

\subsubsection{Scanning Electron Microscopy (SEM) and Energy Dispersive Spectroscopy (EDS)}

The morphology of the solid phases was determined by a field emission scanning electron microscope FE-SEM; JEOL JSM-7000F microscope operated at $5.0 \mathrm{kV}$ (Tokyo, Japan). For SEM analysis a required amount of powder was placed on a sample holder covered with carbon glue and the excess powder was removed by gentle nitrogen gas flow. EDS analysis was performed by Eds Inca Energy 350 system (Oxford Instruments, High Wycombe, UK) connected to FE-SEM.

\subsubsection{Atomic Absorption Spectrometry (AAS)}

For AAS analysis all samples were dissolved in $\mathrm{HCl}\left(\right.$ conc): $\mathrm{H}_{2} \mathrm{O}(1: 1 v / v)$ solution. Determination of $\mathrm{Mg}$ content was performed on AAnalyst 200 Atomic Absorption Spectrometer (PerkinElmer, Waltham, MA, USA).

\subsubsection{Thermogravimetric Analysis (TGA)}

Thermogravimetric analysis was performed using a Mettler TG 50 thermobalance equipped with a TC 10 TA processor (Mettler Toledo, Columbus, OH, USA). The samples were heated over the temperature range of $25-300^{\circ} \mathrm{C}$ at a rate of $10^{\circ} \mathrm{C} / \mathrm{min}$ and under a dynamic air atmosphere. The weight loss was recorded as a function of temperature.

\subsubsection{Electron Paramagnetic Resonance (EPR) Spectroscopy}

The EPR spectra of all samples were recorded on a Varian E-109 EPR spectrometer (Palo Alto, CA, USA) operating at $9.29 \mathrm{GHz}$, equipped with a Bruker ER 041 XG microwave 
bridge. Spectra were acquired using EW (EPRWare) Scientific Software [32]. The magnetic field was calibrated with a manganese standard reference $\left(\mathrm{Mn}^{2+}\right.$ in $\left.\mathrm{MgO}\right)$. The spectra acquisition of samples that were immersed was performed at room temperature. The behaviour of species induced by gamma radiation was studied at $343 \mathrm{~K}, 353 \mathrm{~K}, 363 \mathrm{~K}$ and $373 \mathrm{~K}$ for all samples without previous immersion in media. Temperature was controlled using a Bruker ER 4111 VT variable-temperature unit with a $\mathrm{N}_{2}$ (cold/normal) gas flow. The spectroscopic parameters were as follows: modulation amplitude $0.11 \mathrm{mT}$, magnetic field sweep $20 \mathrm{mT}$, central magnetic field $330.8 \mathrm{mT}$, and microwave field power $1.99 \mathrm{~mW}$. Spectra were divided by the mass of the corresponding sample and the receiver gain applied for the single measurement so they could be properly compared. When comparing the signal intensities, the parameter of interest was the double integral of the EPR signal.

\section{Results}

\subsection{Characterisation of HAPs before and after Irradiation}

PXRD patterns, FTIR spectra and SEM micrographs of non-substituted HAP and Mg-substituted HAP, before and after irradiation are shown in Figures 1-3, respectively.

Corrected simulated body fluid
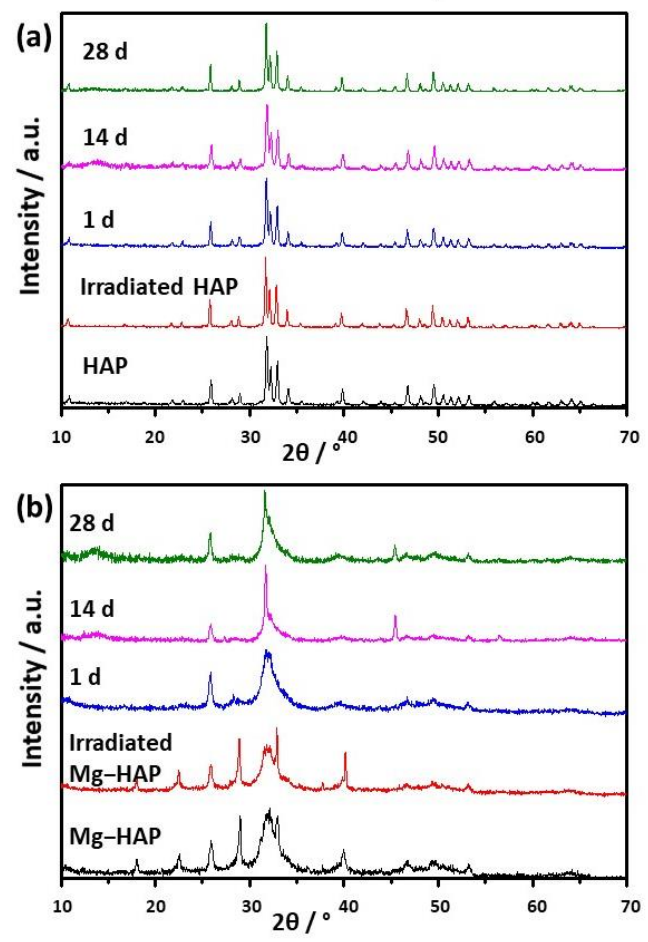

Saline solution
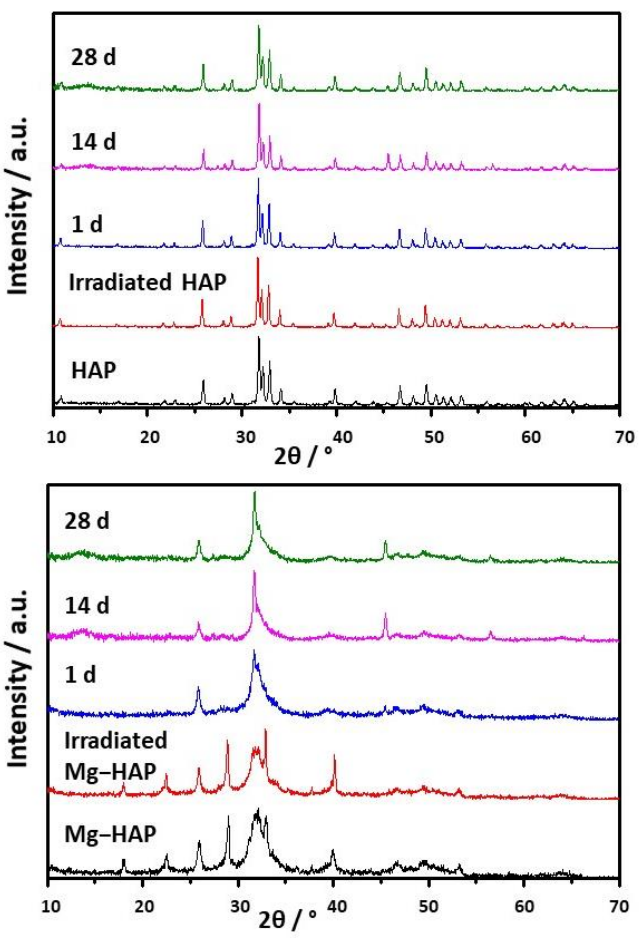

Figure 1. PXRD patterns of (a) non-substituted hydroxyapatite (HAP) and (b) Mg-substituted HAP (Mg-HAP) starting powder, powder irradiated to $25 \mathrm{kGy}$, and powders after immersion in corrected simulated body fluid (c-SBF) and saline solution (SS) for $1-28$ days at $37^{\circ} \mathrm{C}$.

The powder diffraction pattern of synthesized, non-doped HAP contains a number of sharp peaks, indicating good crystallinity (Figure 1a). The most prominent peaks were detected at $2 \theta 10.86^{\circ}, 25.91^{\circ}, 31.81^{\circ}, 32.25^{\circ}$ and $32.95^{\circ}$ corresponding to (100), (002), (211), (112) and (300) reflections of HAP (Table S1, JCPDS 09-0432). In the FTIR spectra (Figure 2a) vibrational bands of phosphate and hydroxy groups characteristic of HAP were observed (Table S2). The vibrations of phosphate groups were observed at $1087 \mathrm{~cm}^{-1}$ and $1024 \mathrm{~cm}^{-1}$ corresponding to $v_{3 \mathrm{a}}$ and $v_{3 \mathrm{c}}$ triply degenerate asymmetric stretching mode of $\mathrm{P}-\mathrm{O}$ bonds, respectively; at $963 \mathrm{~cm}^{-1}$ corresponding to $v_{1}$ non-degenerate symmetric stretching mode of P-O bonds; at $599 \mathrm{~cm}^{-1}$ and $564 \mathrm{~cm}^{-1}$ corresponding to $v_{4 \mathrm{a}}$ and $v_{4 \mathrm{c}}$ triply degenerate bending mode of O-P-O bonds, respectively; and at $474 \mathrm{~cm}^{-1}$ corresponding to $v_{2 a}$ double degenerate bending mode of O-P-O bonds [33]. Two bands characteristic of vibration of the 
hydroxy group were observed, one at $3573 \mathrm{~cm}^{-1} v_{\mathrm{s}}$ corresponding to the stretching mode and the other at $629 \mathrm{~cm}^{-1}$ corresponding to the vibrational mode of the hydroxyl group [33]. A SEM micrograph revealed that HAP was formed in the shape of irregular prismatic crystals (Figure 3). EDS analysis confirmed the presence of Ca, P and O (Figure S1a).
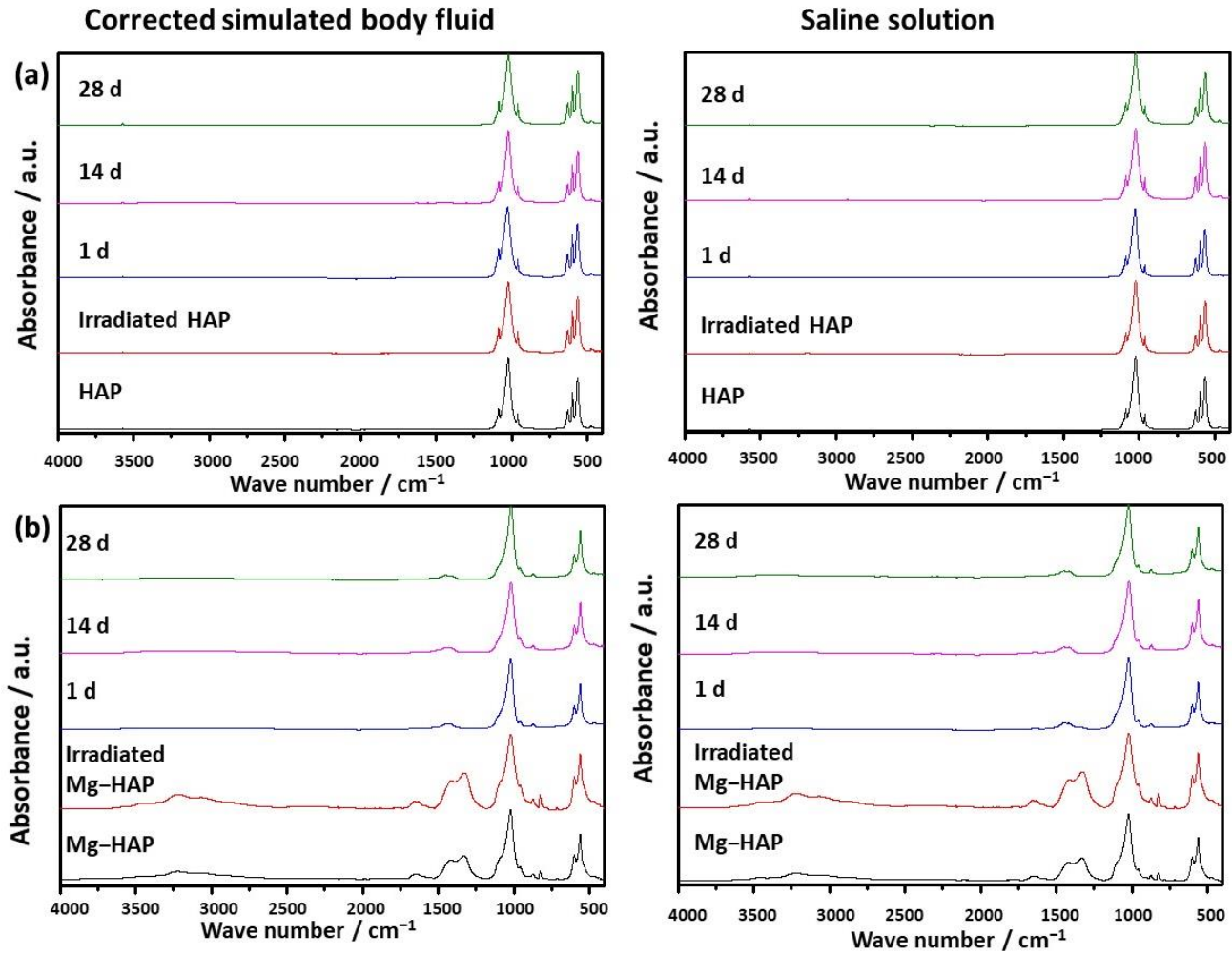

Figure 2. FTIR spectra of (a) non-substituted hydroxyapatite (HAP) and (b) Mg-substituted HAP (Mg-HAP) starting powder, powder irradiated to $25 \mathrm{kGy}$, and powders after immersion in corrected simulated body fluid (c-SBF) and saline solution (SS) for $1-28$ days at $37^{\circ} \mathrm{C}$.

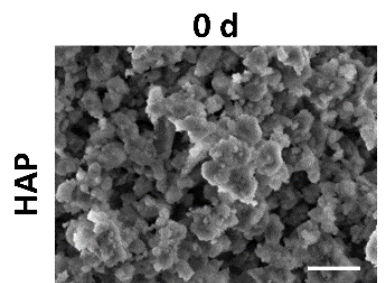

Corrected simulated body fluid

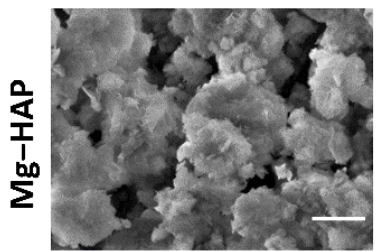

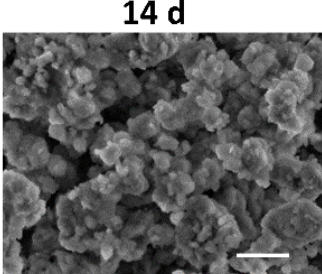

$28 \mathrm{~d}$
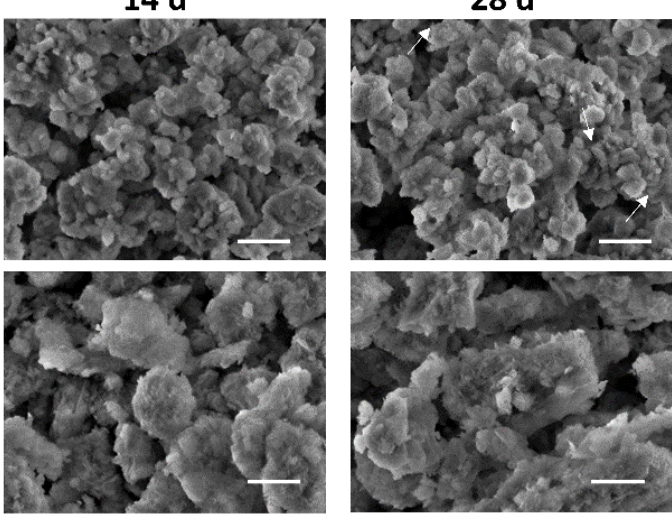

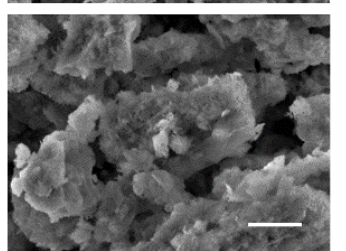

Saline solution
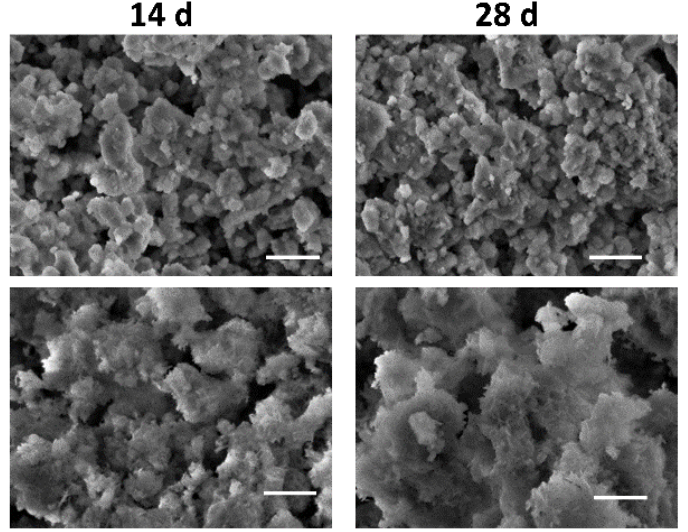

Figure 3. SEM images of non-substituted hydroxyapatite (HAP) and Mg-substituted HAP (Mg-HAP) after immersion in corrected simulated body fluid (c-SBF) and saline solution (SS) for 14-28 days at $37^{\circ} \mathrm{C}$. Scale bar is $1 \mu \mathrm{m}$.

The PXRD pattern of Mg-HAP contains the peaks characteristic of HAP (Figure 1b), the most intensive at $2 \theta 25.90^{\circ}, 29.01^{\circ}, 31.19^{\circ}, 32.17^{\circ}$ and $32.95^{\circ}$ corresponding to (002), (210), (211), and (112) reflections of HAP (Table S3). The peaks are broader compared to the non-substituted HAP (Figure 1a) in accordance with previous studies [14,34-36]. 
This is especially pronounced for the peaks in $2 \theta$ region $30-35^{\circ}$. Additionally, several lowintensity HAP peaks were not observed. In addition to lower crystallinity, this indicates the formation of the apatitic phase $[1,36,37]$. Together with HAP peaks, a low-intensity peak at $2 \theta 37.71^{\circ}$ characteristic of $\mathrm{Mg}(\mathrm{OH})_{2}$ was observed [38,39]. In addition to the phosphate and water bands observed in the FTIR spectrum of non-substituted HAP (Figure 2a), bands corresponding to the vibration of $\mathrm{H}_{2} \mathrm{O}$ at $3564-3000 \mathrm{~cm}^{-1}$ and $1633 \mathrm{~cm}^{-1}, \mathrm{CO}_{3}^{2-}$ bands at $1426 \mathrm{~cm}^{-1}, 1321 \mathrm{~cm}^{-1}$ and $873 \mathrm{~cm}^{-1}$ [14,38], a $\mathrm{P}_{2} \mathrm{O}_{7}^{4-}$ band at $828 \mathrm{~cm}^{-1}$, and a band at $715 \mathrm{~cm}^{-1}$ were observed (Figure $2 \mathrm{~b}$ ). The presence of a water band, in the region 3564-3000 $\mathrm{cm}^{-1}$, indicates the higher affinity of Mg-HAP surfaces for binding water molecules [40]. In addition, the hyperfine structure of the phosphate bands in the region 1134-914 $\mathrm{cm}^{-1}$ was lost, also indicating the lower crystallinity of Mg-HAP compared to HAP. A SEM micrograph revealed the formation of aggregated leaf-like crystals (Figure 3), while EDS spectra confirmed the presence of magnesium in the material (Figure S1b). The content of $\mathrm{Mg}$ in the sample was $0.25 \%$ as determined by AAS.

The EPR spectra (not shown) of non-irradiated HAP and Mg-substituted HAP contained no signal, which confirmed the purity of synthesis and the absence of metal and trace ions. Therefore, samples were irradiated to $25 \mathrm{kGy}$, the golden dosage usually used for sterilization of biomedical materials [41]. As expected, no change in the structure and composition of both samples was detected after irradiation, as shown in the PXRD patterns and FTIR spectra (Figures 1 and 2, Tables S1-S4).

The EPR spectra of non-substituted HAP and Mg-substituted HAP irradiated to $25 \mathrm{kGy}$ are shown in Figure 4. Two dominant signals observed in EPR spectra of both samples were assigned to $\mathrm{CO}_{2}^{-}$and $\mathrm{NO}_{3}^{2-}$ radicals. The $\mathrm{CO}_{2}^{-}$radical was most probably incorporated during the synthesis performed in the presence of air [42,43]. The g-values of $\mathrm{CO}_{2}^{-}$signals of non-substituted HAP and Mg-substituted HAP differ within the measurement error and amount to $g_{x}=2.0035 \pm 0.0002, g_{z}=2.0015 \pm 0.0002$ and $g_{y}=1.9976 \pm 0.0002$, which is in accordance with previous EPR studies concerned with free radicals and defects in calcium phosphates, bones and tooth enamel $[21,22,43-47]$. Furthermore, $\mathrm{NO}_{3}^{2-}$ radical was probably incorporated during synthesis and it was detected primarily in non-substituted HAP. Its g-values were: $g_{x}=g_{y}=2.0057 \pm 0.0002$ and $g_{z}=2.0017 \pm 0.0002$, in accordance with already reported values $[48,49]$.

In addition to these two dominant signals, EPR spectra of Mg-substituted HAP compared to EPR spectra of non-substituted HAP show additional peaks of varying intensity in the magnetic field range from $328.67 \mathrm{mT}$ to $331.01 \mathrm{mT}$, which correspond to the g-value range from 2.0199 to 2.0056. The assignation of each of these peaks is challenging, time demanding, and out of the scope of this paper. The lack of published research concerning EPR spectra of Mg-substituted HAP makes this task even more arduous. However, the EPR spectrum of Mg-substituted HAP was similar to that of bovine hydroxyapatite reported by Kusrini and Sontang [50].

\subsection{Behaviour in Model Media}

Upon immersion of HAP in both c-SBF and saline solution, after 14 days a lowintensity amorphous maximum was detected in the range $2 \theta$ app. $13^{\circ}-15^{\circ}$. The intensity of this maximum decreased with time, which could indicate the formation of a new phase (Figure 1a). No changes were observed in the FTIR spectra (Figure 2 and Table S2). In addition, no significant change in the morphology of HAP was observed (Figure 3), except after 28 days of immersion in SBF. In that case, the small and thin leaf-like crystals were sparsely formed on the surface of the HAP crystals (denoted by arrows in Figure 3). The observed behaviour could be a consequence of HAP being the most thermodynamically stable $\mathrm{CaP}$ phase in physiological conditions [1,51]. 


\section{Corrected simulated body fluid}

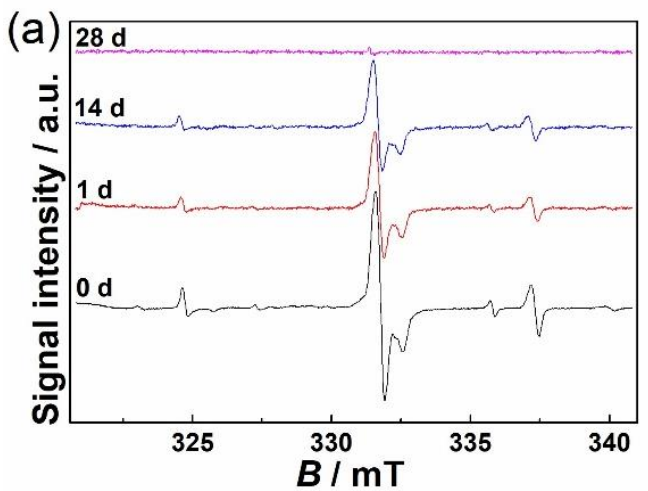

(b)



Saline solution
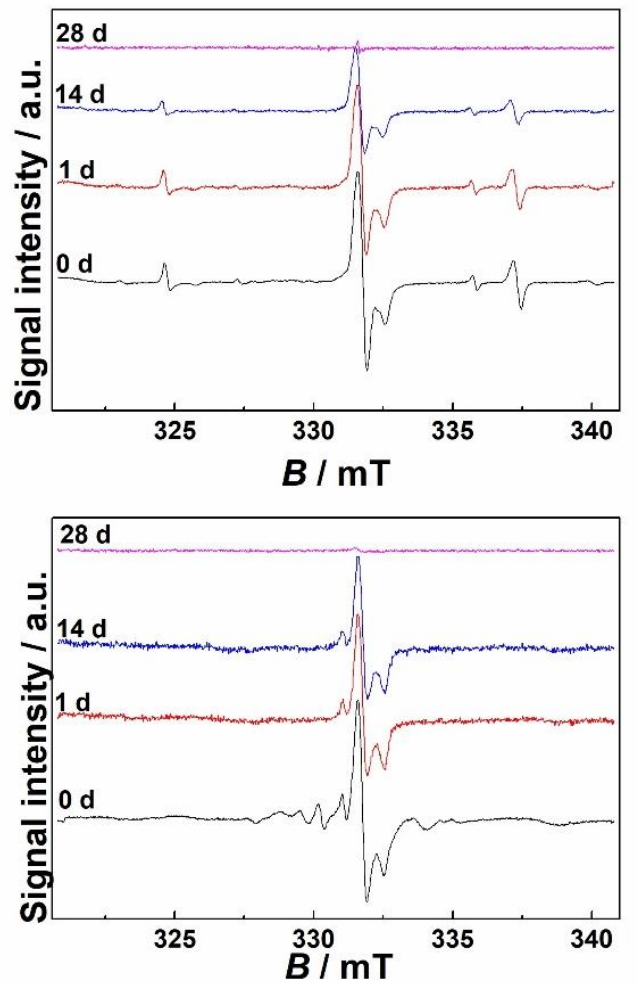

Figure 4. EPR spectra of (a) non-substituted hydroxyapatite (HAP) and (b) Mg-substituted HAP (Mg-HAP) irradiated to $25 \mathrm{kGy}$ and after immersion in corrected simulated body fluid (c-SBF) and saline solution (SS) for $1-28$ days at $37^{\circ} \mathrm{C}$.

In the case of Mg-HAP, upon immersion in c-SBF and saline solution, peaks corresponding to (110), (111), (210), (112) and (310) HAP reflections, as well as a low-intensity $\mathrm{Mg}(\mathrm{OH})_{2}$ peak, disappeared after 1 day of immersion (Figure $\left.1 \mathrm{~b}\right)$. The low-intensity amorphous maximum in $2 \theta$ range app. $12-15^{\circ}$ was observed after 14 days of immersion in both media, similar to non-substituted HAP. In addition, low-intensity peaks at around $45.5^{\circ}$ and $56.5^{\circ}$, not present in untreated Mg-HAP, were also detected. The FTIR spectra of the samples immersed in both media did not contain a water vibration band in the region of $3564-3000 \mathrm{~cm}^{-1}$, a band at $1633 \mathrm{~cm}^{-1}$, a band at $828 \mathrm{~cm}^{-1}$, or a $\mathrm{P}_{2} \mathrm{O}_{7}^{4-}$ band at $715 \mathrm{~cm}^{-1}$ which were present in the spectra of untreated Mg-HAP (Figure $2 \mathrm{~b}$ and Table S4). In addition, the intensity of $C O$ bands in the region of $1450-1330 \mathrm{~cm}^{-1}$ decreased compared to the intensity of corresponding phosphate bands in the region of $1100-1000 \mathrm{~cm}^{-1}$. The leaf-like crystals appeared more developed after immersion in c-SBF for 14 and 28 days than in saline solution after 28 days (Figure 3). No significant change was observed in the morphology of the sample immersed in saline solution after 28 days.

The EPR signals of both HAP and Mg-HAP immersed in model media decreased over time and after 28 days they were completely or mostly absent (Figure 4). The fading or disappearance of signals implies the possibility of some form of sample stabilization in conditions that imitate physiological ones, which is quite promising considering the possible medical applications of hydroxyapatites, both substituted and unsubstituted. In Figure 5 the decay of the double integral of the signal expressed in \% relative to the sample that was only irradiated to $25 \mathrm{kGy}$ is shown. The difference between the signal decrease of the samples treated with c-SBF and saline solution is within the estimated measurement error when compared 28 days after immersion. This indicates that although the decay rates are different for the two samples, the two media could have a similar effect on radiationinduced radicals in HAP and Mg-substituted HAP and could be a prediction of similar 
behaviour when applied as hard tissue regeneration implants, despite the differences in the structure and composition of the two samples.

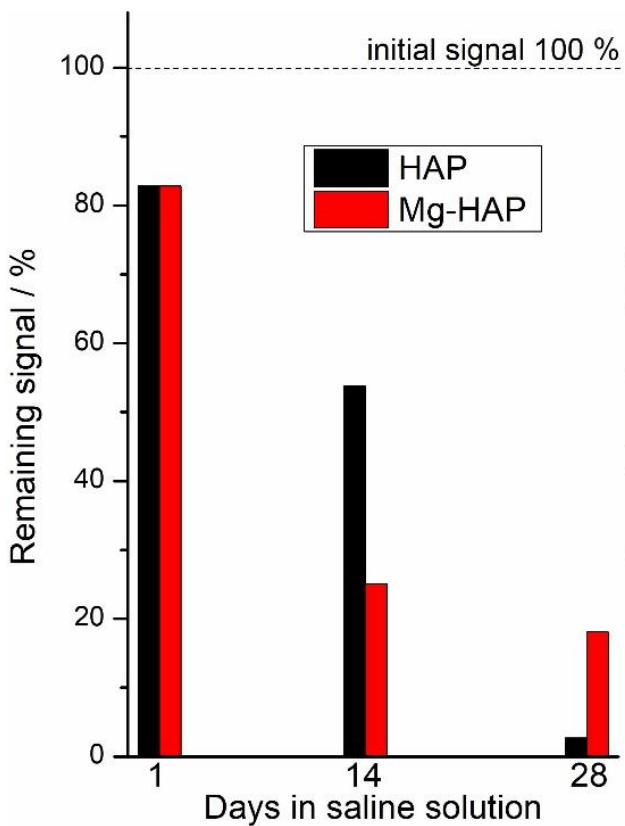

(a)

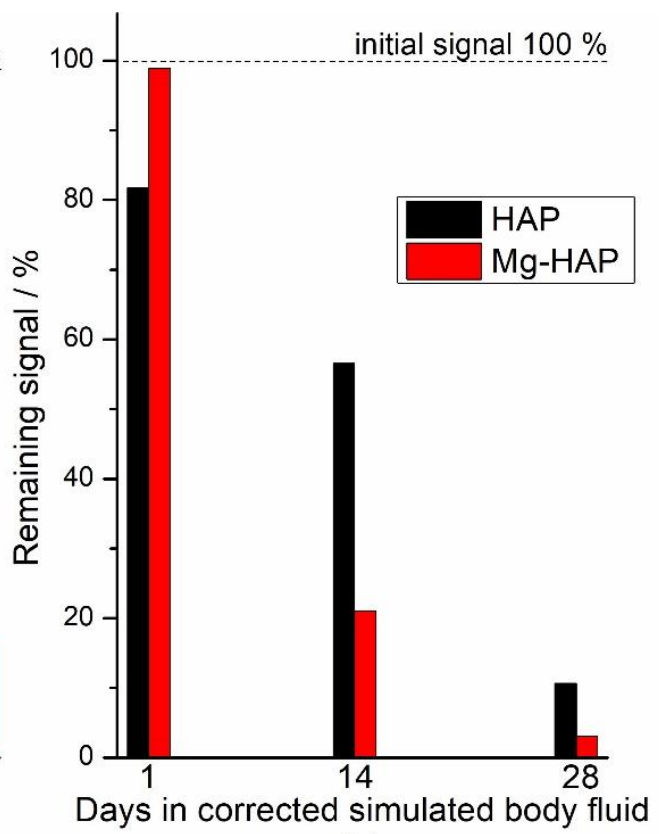

(b)

Figure 5. Dependence of double integral of the signal on the number of days of immersion (a) corrected simulated body fluid (c-SBF) and (b) saline solution (SS) at $37^{\circ} \mathrm{C}$ of non-substituted hydroxyapatite (HAP) and Mg-substituted HAP (Mg-HAP) irradiated to $25 \mathrm{kGy}$.

\subsection{Thermal Behaviour-Accelerated Ageing}

In order to determine the stability of radicals that were formed due to sterilization with gamma radiation, EPR spectra of non-substituted HAP and Mg-substituted HAP were recorded at four different temperatures $(343 \mathrm{~K}, 353 \mathrm{~K}, 363 \mathrm{~K}$ and $373 \mathrm{~K})$ during at least $2 \mathrm{~h}$ of heating. These results could provide additional information about the behaviour of free radicals in conditions such as storage and transport [27].

To determine that no structural or compositional changes occurred in HAPs, PXRD patterns were recorded after $2 \mathrm{~h}$ of heating at the desired temperature (Figure 6). In addition, a thermogravimetric analysis of both samples was performed to show any possible change that could be manifested through loss in mass (Figure S2). Such data could narrow the possible phenomena underlying the results obtained by EPR.
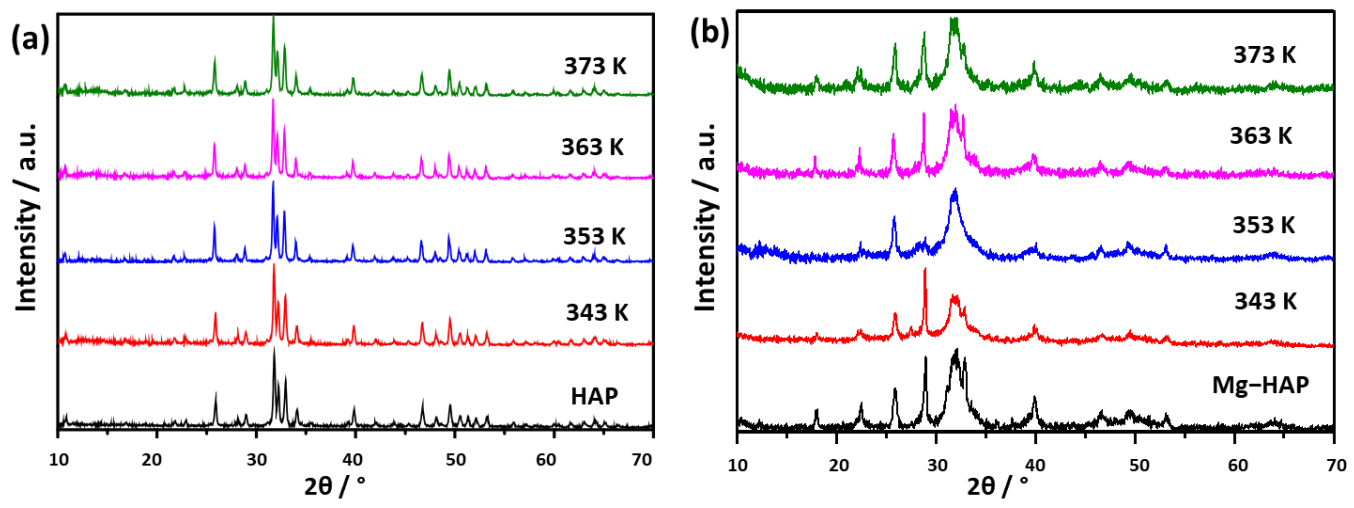

Figure 6. PXRD patterns of (a) non-substituted hydroxyapatite (HAP) and (b) Mg-substituted HAP (Mg-HAP) irradiated to $25 \mathrm{kGy}$ after heating at $343 \mathrm{~K}, 353 \mathrm{~K}, 363 \mathrm{~K}$ and $373 \mathrm{~K}$ for $2 \mathrm{~h}$. 
No changes were observed in HAP patterns (Figure 6a). In the case of Mg-HAP (Figure $6 \mathrm{~b}$ ) the intensity of the peak at $2 \theta 32.95^{\circ}$ varied with temperature. Since no direct relationship between the changes in intensity and increase in temperature could be drawn, this change could be caused by the inhomogeneity of the sample.

To confirm that no substantial change occurred due to the heating up to $373 \mathrm{~K}$, TGA analysis was performed (Figure S2). In the investigated temperature range, HAP lost less than $2 \%$ in mass while Mg-substituted HAP lost about $6 \%$ of its mass. The difference can be ascribed to the greater water content in Mg-HAP [40], as also shown from the FTIR spectrum (Figure 2b). This is in accordance with the previously reported behaviour of non-substituted and Mg-substituted HAP [52,53].

Figure 7 shows the change relative to the initial value in the double integral of EPR spectra of the two samples at four different temperatures. The first finding that can be seen is that the EPR signals of non-substituted HAP and Mg-substituted HAP follow different trends at different temperatures.
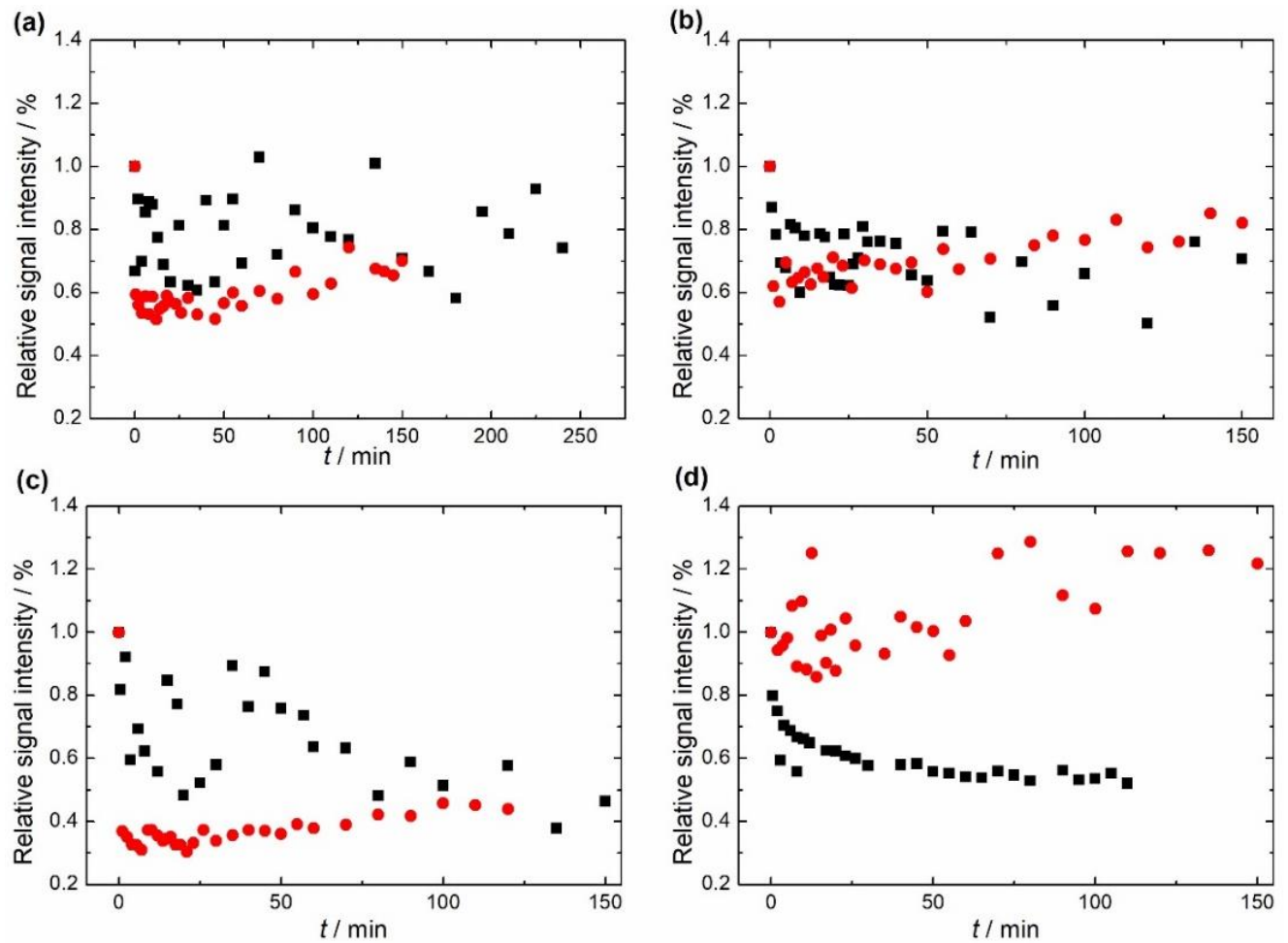

Figure 7. Dependence of the double integral of EPR spectra of non-substituted hydroxyapatite (HAP), black squares, and Mg-substituted HAP (Mg-HAP), red circles, at (a) $343 \mathrm{~K}$, (b) $353 \mathrm{~K}$, (c) $363 \mathrm{~K}$ and (d) $373 \mathrm{~K}$.

The relative signal intensity of non-substituted HAP decreased as the sample was subjected to a temperature higher than room temperature, but this trend is not yet prominent and is hardly noticeable at $343 \mathrm{~K}$ and $353 \mathrm{~K}$, as seen in Figure 7. On the other hand, a clearer fading of the signal is seen at $363 \mathrm{~K}$ and $373 \mathrm{~K}$. In addition, the shape and relative intensity of the signal did not change, this was also the case for Mg-substituted HAP. As far as the Mg-substituted HAP is concerned, a quite unexpected phenomenon was revealed. At temperatures of $343 \mathrm{~K}, 353 \mathrm{~K}$, and $363 \mathrm{~K}$ the signal faded to about $30-60 \%$ and, after that, increased to about $50-75 \%$ relative to the initial value. This change was visible at about 7-12 min from the beginning of heating. When the sample was kept at $373 \mathrm{~K}$, the initial fading was not that noticeable as it is within measurement error. Still, the increase of the signal was the most intense in this case. The final signal was even stronger than the initial one and reached about $125 \%$ relative to the initial value. 
Although various mechanisms by which $\mathrm{Mg}$ is absorbed/incorporated during hydroxyapatite crystallization have already been studied [12], the influence of this dopant on the EPR signal of substituted hydroxyapatite is still not thoroughly understood, particularly at temperatures above room temperature. Moreover, the exact location of the $\mathrm{CO}_{2}^{-}$and $\mathrm{CO}_{3}^{-}$ radicals in biological and synthetic apatites is still under debate. They could substitute the hydroxy group, the phosphorous tetrahedron or neutral $\mathrm{CO}_{2}$ that could be found on the surface of crystallites. As reported by Rudko et al., a redistribution of the signal contribution of axial and orthorhombic $\mathrm{CO}_{2}^{-}$radicals in pristine $\mathrm{HAP}$ is seen above $200{ }^{\circ} \mathrm{C}$ [54]. This is most probably connected to the sharp loss in the mass of Mg-substituted HAP reported in this temperature range. The authors noted that not only did the thermally induced and radiation-induced radicals give the same signal, but also the same was observed for the synthetic and biological hydroxyapatites which additionally confirmed the great similarity between these two materials. No matter the phenomenon, it appears that magnesium influences HAP in such a manner that it amplifies some heat-related behaviour, and maybe even lower the temperatures at which such effects take place. It is known that the removal of water during drying can result in subsequent shrinkage of hydroxyapatite lattice and because of local variations in water content, small structural changes may develop [55]. Nevertheless, the observed loss in mass, which is probably related to water loss [53,56], confirmed by TGA is relatively small and did not induce a change in the detected EPR line width which would be expected for this kind of effect (Figure S3).

Several studies revolve around the interaction and properties of magnesium and hydroxyapatite under different conditions. All of them demonstrate destabilization of the crystal HAP structure. For example, Bertoni et al. took advantage of the structural disorder which favoured the adsorption of polyacrylic acid [57]. Moreover, it was shown that $\mathrm{Mg}$-substitution in the lattice led to the weak intergranular bond formation and the improvement of plastic properties in doped HAP ceramics. The introduction of this cation promoted granular bond weakening and changed the fracture mode for prepared ceramics [58]. Suciu et al. reported an interesting effect of Mg substitution of HAP. The doped material showed an increase in thermal conductivity directly related to the increase in magnesium percentage [59]. This observation may give an insight into the different phenomena developing in pristine and $\mathrm{Mg}$-substituted HAP presented in this study.

Unfortunately, articles published to date have not described the relationship between the presence of magnesium, free radicals induced by gamma radiation, and their behaviour at temperatures just above room temperature as in our case. On the other hand, Mgsubstituted HAP is comparable to tooth enamel and giving attention to articles on this material could offer a new perspective on the effect observed in this study. Vorona et al. observed an increase in the EPR intensity of the main radical species, i.e., $\mathrm{CO}_{2}^{-}$radical, in the tooth enamel of approximately $40 \%$ at $180{ }^{\circ} \mathrm{C}$ [60]. The absorbed dose of the samples was $3 \mathrm{kGy}$ which is approximately eight times lower than the "golden" sterilization dose used in our study. The authors attributed this radiation sensitivity effect in tooth enamel to annealing, but with the explanation that below $230{ }^{\circ} \mathrm{C}$ the conversion of disordered $\mathrm{CO}_{2}^{-}$radical species into oriented ones occurred. The observation was accompanied by changes of the EPR line shape for $160^{\circ} \mathrm{C}<\mathrm{T}_{\text {annel. }}<230^{\circ} \mathrm{C}$ which was not observed in our case (Figure S3). This effect can be associated with the $\mathrm{Mg}$ content, as it is well known to play an important role in tooth enamel biomineralization. The $\mathrm{Mg}$ content significantly varies within the enamel of different animal species and correspondingly influences other properties such as hardness $[16,61,62]$. Due to the previously mentioned reasons, a further comparison was not possible. Furthermore, Ishchenko et al. observed a slight EPR intensity increase during monitoring temperature changes of the carbonate structure in tooth enamel in the temperature interval $\left(\mathrm{T}_{\text {annel. }}<250^{\circ} \mathrm{C}\right)$ [63]. One of the proposed explanations of this effect was the annealing-induced decay of electron traps which can capture the radiation-induced secondary electrons that participate in the formation of $\mathrm{CO}_{2}^{-}$radicals. Therefore, the decay of traps enhances the radiation-induced signal. The nature of these traps has not yet been clarified, but weakly bound water can escape from the surface and 
subsurface regions of crystallites. Therefore, the authors assumed that the above-mentioned electron traps have a surface or subsurface origin and are related to the complexes that include water [63]. In our case, the loss in water is probably not significant enough to cause similar changes and would manifest itself as a change in the signal shape, which was not observed (Figure S3). An additional explanation of the observed increase in the amount of $\mathrm{CO}_{2}^{-}$radicals include a decrease in the volume of amorphous regions in HAP during annealing [64]. From NMR results, it is proposed that carbonate in these regions cannot be transformed into $\mathrm{CO}_{2}^{-}$radicals under irradiation, but the transformation of amorphous regions into the ordinary structure of $\mathrm{HAP}$ with $\mathrm{CO}_{2}^{-}$ions can increase the total number of the latter and, respectively, the amount of related $\mathrm{CO}_{2}^{-}$radicals, and accordingly an increase in the EPR intensity.

When it comes to the EPR signal of Mg-substituted HAP in this study, it is a great challenge to explain the reported results since the relationship between the presence of magnesium and the free radicals has not yet been established. Moreover, the comprehension of the simultaneous existence of these species is additionally tangled by the fact that similar results were not published to this day. One may speculate about the existence of two different competing kinetic patterns in $\mathrm{Mg}$-substituted HAP that take place just above room temperature: recombination and creation of free radicals. The lack of linewidth changes in the EPR signal of Mg-substituted HAP during $2 \mathrm{~h}$ of heating at $343 \mathrm{~K}, 353 \mathrm{~K}$, $363 \mathrm{~K}$ and $373 \mathrm{~K}$ support the hypothesis that there is no change in the motional dynamics of radicals, as well as lack of the changes in the spectral shape as shown in Figure S3a. Figure S3b shows that there is no correlation between the time the Mg-substituted HAP was being heated and the relative position of the peaks $\left(R^{2}=0.1002\right)$. These processes could be caused by the presence of magnesium since such a phenomenon does not manifest in non-substituted HAP. In contrast, non-substituted HAP shows some changes in the EPR spectrum only at higher temperatures, as pointed out in the literature [54].

As far as the accelerated ageing analysis is concerned, Mg-substituted HAP prepared as described in this study should be further improved and investigated before considering preclinical trials. This valuable information would not be available if EPR measurements were not performed, as seen from the PXRD and FTIR results, therefore, it demonstrates the power of a technique that could be adopted more often in similar studies.

\section{Conclusions}

Mg-substituted HAPs are receiving increasing attention as biomimetic and bioactive hard tissue regeneration materials due to the presence of $\mathrm{Mg}^{2+}$ ions with beneficial biological effects. Investigating the properties of these materials is crucial to determine their true potential for biomedical application. Although the number of studies considering Mg-substituted HAPs is increasing, there are several topics that are rarely discussed although they are of utmost importance for the successful application of implant materials. These include the stability of the material upon sterilization, in model media, and during accelerated ageing.

The influence of $\gamma$-irradiation, as a typical sterilization technique, followed by immersion in corrected simulated body fluid and saline solution, as well as accelerated ageing, were studied for non-substituted HAP and Mg-substituted HAP considering composition, structure, and local order.

Irradiation does not affect the composition and structure of HAPs. Upon immersion in model media, the small amount of by-products from synthesis disappeared after one day leaving Mg-HAP as the only remaining phase. Similarly, the radical signals in the EPR spectra fade or completely disappear after 28 days in model media. This could indicate that, despite the differences in structure and composition of these two HAPs, both are undergoing a kind of stabilization in the conditions imitating physiological ones.

However, quite unusual, and previously unreported behaviour of EPR spectra was observed for Mg-substituted HAP after irradiation at temperatures up to $373 \mathrm{~K}$ regarding 
two competing kinetic patterns, but this was not observed for non-substituted HAP. This will be the central topic of a future study.

Overall, the obtained results indicate that Mg-substituted HAP has a good potential for biomedical applications considering its behaviour in media that mimic physiological conditions, but its behaviour under certain storage and transport conditions should be studied in more detail.

Supplementary Materials: The following supporting information can be downloaded at: https: / / www.mdpi.com/article/10.3390/cryst12020297/s1, Figure S1. EDS images of (a) hydroxyapatite (HAP) and (b) Mg-substituted; Figure S2. TGA curves of non-substituted hydroxyapatite (HAP) and Mg-substituted HAP (Mg HAP); Figure S3. (a) EPR spectra of irradiated Mg-substituted hydroxyapatite heated at $373 \mathrm{~K}$ at different times and (b) peak-peak linewidth of $\mathrm{CO}_{2}^{-}$radical; Table S1. Assignation of peaks in PXRD patterns of hydroxyapatite; Table S2. Assignation of IR bands in FTIR spectra of hydroxyapatite; Table S3. Assignation of peaks in PXRD patterns of Mg-substituted hydroxyapatite; Table S4. Assignation of IR bands in FTIR spectra of Mg-substituted hydroxyapatite.

Author Contributions: Conceptualization, N.M.-S.; methodology, B.P., A.L., I.E. and N.M.-S.; formal analysis, M.V., T.G., M.D.S., I.E. and N.M.-S.; investigation, M.V., T.G., B.P., N.S., T.A.J., D.K., N.M.M., A.L., M.D.S., I.E. and N.M.-S.; writing-original draft preparation, T.G., M.V., I.E. and N.M.-S.; writing-review and editing, I.E. and N.M.-S.; visualization, T.G., M.V., I.E. and N.M.-S.; funding acquisition, B.P., A.L. and M.D.S. All authors have read and agreed to the published version of the manuscript.

Funding: This study was supported by the Croatian Science Foundation, Grant HRZZ- IP-201801-1493, Ministry of Science and Education, Croatian-Serbian bilateral project "Ion substituted hydroxyapatites for bone tissue engineering" and COGITO project "Systematic investigation of adsorption of proteins on calcium phosphate based bioceramics for bone tissue engineering".

Data Availability Statement: The data are available within the article or its Supplementary Materials.

Acknowledgments: D.K. and N.M.M. gratefully acknowledges financial support from the Croatian Science Foundation Grant HRZZ- IP-2013-11-5055.

Conflicts of Interest: The authors declare no conflict of interest.

\section{References}

1. Dorozhkin, S.V. Calcium Orthophosphates in Nature, Biology and Medicine. Materials 2009, 2, 399-498. [CrossRef]

2. Omema, U.; Khalid, H.; Chaudhry, A.A. Magnesium-substituted hydroxyapatite. In Handbook of Ionic Substituted Hydroxyapatites; Woodhead Publishing Series in Biomaterials; Khan, A.S., Chaudhry, A.A., Eds.; Woodhead Publishing: Sawston, UK, 2020; pp. 197-216, ISBN 978-0-08-102834-6. [CrossRef]

3. Gibson, I.R. Natural and Synthetic Hydroxyapatites. In Biomaterials Sciences. Materials in Medicine, 4th ed.; Wagner, W.R., Sakiyama-Elbert, S.E., Zhang, G., Yaszemski, M.J., Eds.; Elsevier Inc.: Amsterdam, The Netherlands, 2020; pp. 307-317, ISBN 978-0-12-816137-1. [CrossRef]

4. Fiume, E.; Magnaterra, G.; Rahdar, A.; Verné, E.; Baino, F. Hydroxyapatite for Biomedical Applications: A Short Overview. Ceramics 2021, 4, 542-563. [CrossRef]

5. Kono, T.; Sakae, T.; Nakada, H.; Kaneda, T.; Okada, H. Confusion between Carbonate Apatite and Biological Apatite (Carbonated Hydroxyapatite) in Bone and Teeth. Minerals 2022, 12, 170. [CrossRef]

6. Bigi, A.; Boanini, E.; Gazzano, M. Ion substitution in biological and synthetic apatites. In Biomineralization and Biomaterials; Aparicio, C., Ginebra, M.-P., Eds.; Woodhead Publishing: Boston, UK, 2016; pp. 235-266. ISBN 978-1-78242-338-6. [CrossRef]

7. Cacciotti, I. Cationic and Anionic Substitutions in Hydroxyapatite. In Handbook of Bioceramics and Biocomposites; Antoniac, I.V., Ed.; Springer International Publishing: Cham, Switzerland, 2016; pp. 145-211, ISBN 978-3-319-12460-5. [CrossRef]

8. Bosch-Rué, Ė.; Díez-Tercero, L.; Rodriguez-Gonzalez, R.; Pérez, R.A. Multiple Ion Scaffold-Based Delivery Platform for Potential Application in Early Stages of Bone Regeneration. Materials 2021, 14, 7676. [CrossRef]

9. Sethmann, I.; Luft, C.; Kleebe, H.-J. Development of Phosphatized Calcium Carbonate Biominerals as Bioactive Bone Graft Substitute Materials, Part I: Incorporation of Magnesium and Strontium Ions. JFB 2018, 9, 69. [CrossRef]

10. Cacciotti, I. Multisubstituted hydroxyapatite powders and coatings: The influence of the codoping on the hydroxyapatite performances. Int. J. Appl. Ceram. Technol. 2019, 16, 1864-1884. [CrossRef]

11. LeGeros, R.Z. Calcium phosphates in oral biology and medicine. Monogr. Oral Sci. 1991, 15, 1-201. [CrossRef]

12. Kazakova, G.; Safronova, T.; Golubchikov, D.; Shevtsova, O.; Rau, J.V. Resorbable $\mathrm{Mg}^{2+}$-Containing Phosphates for Bone Tissue Repair. Materials 2021, 14, 4857. [CrossRef] 
13. Lin, S.H.; Zhang, W.J.; Jiang, X.Q. Applications of Bioactive Ions in Bone Regeneration. Chin. J. Dent. Res. 2019, $22,93-104$. [CrossRef]

14. Landi, E.; Tampieri, A.; Mattioli-Belmonte, M.; Celotti, G.; Sandri, M.; Gigante, A.; Fava, P.; Biagini, G. Biomimetic Mg- and $\mathrm{Mg}, \mathrm{CO}_{3}$-substituted hydroxyapatites: Synthesis characterization and in vitro behaviour. J. Eur. Ceram. Soc. 2006, 26, $2593-2601$. [CrossRef]

15. Castiglioni, S.; Cazzaniga, A.; Albisetti, W.; Maier, J. Magnesium and Osteoporosis: Current State of Knowledge and Future Research Directions. Nutrients 2013, 5, 3022-3033. [CrossRef] [PubMed]

16. Šupová, M. Substituted hydroxyapatites for biomedical applications: A review. Ceram. Int. 2015, 41, 9203-9231. [CrossRef]

17. Murzakhanov, F.; Mamin, G.V.; Orlinskii, S.; Goldberg, M.; Petrakova, N.V.; Fedotov, A.Y.; Grishin, P.; Gafurov, M.R.; Komlev, V.S. Study of Electron-Nuclear Interactions in Doped Calcium Phosphates by Various Pulsed EPR Spectroscopy Techniques. ACS Omega 2021, 6, 25338-25349. [CrossRef] [PubMed]

18. Andrés, N.C.; D’Elía, N.L.; Ruso, J.M.; Campelo, A.E.; Massheimer, V.L.; Messina, P. V Manipulation of $\mathrm{Mg}\left(\left(^{2+}\right)\right.$-Ca $\left({ }^{2+}\right)$ Switch on the Development of Bone Mimetic Hydroxyapatite. ACS Appl. Mater. Interfaces 2017, 9, 15698-15710. [CrossRef]

19. Mocanu, A.; Cadar, O.; Frangopol, P.T.; Petean, I.; Tomoaia, G.; Paltinean, G.-A.; Racz, C.P.; Horovitz, O.; Tomoaia-Cotisel, M. Ion release from hydroxyapatite and substituted hydroxyapatites in different immersion liquids: In vitro experiments and theoretical modelling study. R. Soc. Open Sci. 2022, 8, 201785. [CrossRef] [PubMed]

20. Singh, R.; Singh, D.; Singh, A. Radiation sterilization of tissue allografts: A review. World J. Radiol. 2016, 8, 355-369. [CrossRef]

21. Matkovic, I.; Maltar-Strmecki, N.; Babic-Ivancic, V.; Sikiric, M.D.; Noethig-Laslo, V. Characterisation of beta-tricalcium phosphatebased bone substitute materials by electron paramagnetic resonance spectroscopy. Radiat. Phys. Chem. 2012, 81, 1621-1628. [CrossRef]

22. Murzakhanov, F.F.; Grishin, P.O.; Goldberg, M.A.; Yavkin, B.V.; Mamin, G.V.; Orlinskii, S.B.; Fedotov, A.Y.; Petrakova, N.V.; Antuzevics, A.; Gafurov, M.R.; et al. Radiation-Induced Stable Radicals in Calcium Phosphates: Results of Multifrequency EPR, EDNMR, ESEEM, and ENDOR Studies. Appl. Sci. 2021, 11, 7727. [CrossRef]

23. Rahman, N.; Khan, R.; Badshah, S. Effect of x-rays and gamma radiations on the bone mechanical properties: Literature review. Cell Tissue Bank. 2018, 19, 457-472. [CrossRef]

24. Hübner, W.; Blume, A.; Pushnjakova, R.; Dekhtyar, Y.; Hein, H.-J. The Influence of X-ray Radiation on the Mineral/Organic Matrix Interaction of Bone Tissue: An FT-IR Microscopic Investigation. Int. J. Artif. Organs 2005, 28, 66-73. [CrossRef]

25. Bystrova, A.V.; Dekhtyar, Y.D.; Popov, A.I.; Coutinho, J.; Bystrov, V.S. Modified Hydroxyapatite Structure and Properties: Modeling and Synchrotron Data Analysis of Modified Hydroxyapatite Structure. Ferroelectrics 2015, 475, 135-147. [CrossRef]

26. Rokhmistrov, D.V.; Nikolov, O.T.; Gorobchenko, O.A.; Loza, K.I. Study of structure of calcium phosphate materials by means of electron spin resonance. Appl. Radiat. Isot. 2012, 70, 2621-2626. [CrossRef] [PubMed]

27. Fouad, H.; Elleithy, R.; Alothman, O.Y. Thermo-mechanical, Wear and Fracture Behavior of High-density Polyethylene/Hydroxyapatite Nano Composite for Biomedical Applications: Effect of Accelerated Ageing. J. Mater. Sci. Technol. 2013, 29, 573-581. [CrossRef]

28. Desrosiers, M.; Schauer, D.A. Electron paramagnetic resonance (EPR) biodosimetry. Nucl. Instrum. Methods Phys. Res. Sect. B Beam Interact. Mater. Atoms 2001, 184, 219-228. [CrossRef]

29. Chamary, S.; Hautcoeur, D.; Hornez, J.-C.; Leriche, A.; Cambier, F. Bio-inspired hydroxyapatite dual core-shell structure for bone substitutes. J. Eur. Ceram. Soc. 2017, 37, 5321-5327. [CrossRef]

30. Kokubo, T.; Takadama, H. How useful is SBF in predicting in vivo bone bioactivity? Biomaterials 2006, 27, 2907-2915. [CrossRef]

31. Majer, M.; Roguljić, M.; Knežević, Ž.; Starodumov, A.; Ferenček, D.; Brigljević, V.; Mihaljević, B. Dose mapping of the panoramic 60Co gamma irradiation facility at the Ruđer Bošković Institute-Geant4 simulation and measurements. Appl. Radiat. Isot. 2019, 154, 108824. [CrossRef]

32. Morse, P.D., II. Eprware USer Manual, V2.41; Scinetific Softwatre Services: Bloomington, IL, USA, 1990.

33. Koutsopoulos, S. Synthesis and characterization of hydroxyapatite crystals: A review study on the analytical methods. J. Biomed. Mater. Res. 2002, 62, 600-612. [CrossRef]

34. Cacciotti, I.; Bianco, A.; Lombardi, M.; Montanaro, L. Mg-substituted hydroxyapatite nanopowders: Synthesis, thermal stability and sintering behaviour. J. Eur. Ceram. Soc. 2009, 29, 2969-2978. [CrossRef]

35. Kannan, S.; Lemos, I.A.F.; Rocha, J.H.G.; Ferreira, J.M.F. Synthesis and characterization of magnesium substituted biphasic mixtures of controlled hydroxyapatite/ $\beta$-tricalcium phosphate ratios. J. Solid State Chem. 2005, 178, 3190-3196. [CrossRef]

36. Stipniece, L.; Salma-Ancane, K.; Borodajenko, N.; Sokolova, M.; Jakovlevs, D.; Berzina-Cimdina, L. Characterization of Mgsubstituted hydroxyapatite synthesized by wet chemical method. Ceram. Int. 2014, 40, 3261-3267. [CrossRef]

37. Buljan Meić, I.; Kontrec, J.; Domazet Jurašin, D.; Njegić Džakula, B.; Štajner, L.; Lyons, D.M.; Dutour Sikirić, M.; Kralj, D. Comparative Study of Calcium Carbonates and Calcium Phosphates Precipitation in Model Systems Mimicking the Inorganic Environment for Biomineralization. Cryst. Growth Des. 2017, 17, 1103-1117. [CrossRef]

38. Farzadi, A.; Bakhshi, F.; Solati-Hashjin, M.; Asadi-Eydivand, M.; Osman, N.A. abu Magnesium incorporated hydroxyapatite: Synthesis and structural properties characterization. Ceram. Int. 2014, 40, 6021-6029. [CrossRef]

39. Suchanek, W.L.; Byrappa, K.; Shuk, P.; Riman, R.E.; Janas, V.F.; TenHuisen, K.S. Preparation of magnesium-substituted hydroxyapatite powders by the mechanochemical-hydrothermal method. Biomaterials 2004, 25, 4647-4657. [CrossRef] 
40. Sprio, S.; Tampieri, A.; Landi, E.; Sandri, M.; Martorana, S.; Celotti, G.; Logroscino, G. Physico-chemical properties and solubility behaviour of multi-substituted hydroxyapatite powders containing silicon. Mater. Sci. Eng. C 2008, 28, 179-187. [CrossRef]

41. International Atomic Energy Agency. Radiation Sterilization of Tissue Allografts: Requirements for Validation and Routine Control a Code of Practice; International Atomic Energy Agency (IAEA): Vienna, Austria, 2007; ISBN 978-92-0-109002-2.

42. Buljan Meić, I.; Kontrec, J.; Domazet Jurašin, D.; Selmani, A.; Njegić Džakula, B.; Maltar-Strmečki, N.; Lyons, D.M.; Plodinec, M.; Čeh, M.; Gajović, A.; et al. How similar are amorphous calcium carbonate and calcium phosphate? A comparative study of amorphous phases formation conditions. Crystengcomm 2018, 20, 35-50. [CrossRef]

43. Baran, N.P.; Vorona, I.P.; Ishchenko, S.S.; Nosenko, V.V.; Zatovskii, I.V.; Gorodilova, N.A.; Povarchuk, V.Y. NO ${ }^{2-}$ and $\mathrm{CO}_{2}$-centers in synthetic hydroxyapatite: Features of the formation under $\gamma$ - and UV-irradiations. Phys. Solid State 2011, 53, 1891. [CrossRef]

44. Fattibene, P.; Callens, F. EPR dosimetry with tooth enamel: A review. Appl. Radiat. Isot. 2010, 68, 2033-2116. [CrossRef]

45. Ikeya, M. New Applications of Electron Spin Resonance; World Scientific: Singapore, 1993; ISBN 978-981-02-1199-8.

46. Van Doorslaer, S.; Moens, P.; Callens, F.; Matthys, P.; Verbeeck, R. 31P and1H powder ENDOR study of ozonide radicals in carbonated apatites, synthesized from aqueous solutions. Appl. Magn. Reson. 1996, 10, 87-102. [CrossRef]

47. Nosenko, V.V.; Vorona, I.P.; Baran, N.P.; Ishchenko, S.S.; Vysotskyi, B.V.; Krakhmalnaya, T.V.; Semenov, Y.A. Comparative EPR study $\mathrm{CO}_{2}{ }^{-}$radicals in modern and fossil tooth enamel. Radiat. Meas. 2015, 78, 53-57. [CrossRef]

48. Nosenko, V.V.; Vorona, I.P.; Ishchenko, S.S.; Baran, N.P.; Zatovsky, I.V.; Gorodilova, N.A.; Povarchuk, V.Y. Effect of pre-annealing on $\mathrm{NO}_{3}{ }^{2-}$ centers in synthetic hydroxyapatite. Radiat. Meas. 2012, 47, 970-973. [CrossRef]

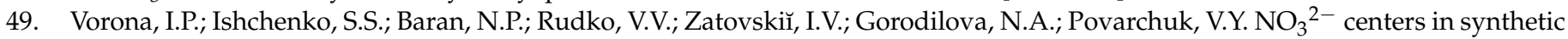
hydroxyapatite. Phys. Solid State 2010, 52, 2364-2368. [CrossRef]

50. Kusrini, E.; Sontang, M. Characterization of X-ray diffraction and electron spin resonance: Effects of sintering time and temperature on bovine hydroxyapatite. Radiat. Phys. Chem. 2012, 81, 118-125. [CrossRef]

51. Wang, L.; Nancollas, G.H. Calcium Orthophosphates: Crystallization and Dissolution. Chem. Rev. 2008, 108, 4628-4669. [CrossRef] [PubMed]

52. Ren, F.; Leng, Y.; Xin, R.; Ge, X. Synthesis, characterization and ab initio simulation of magnesium-substituted hydroxyapatite. Acta Biomater. 2010, 6, 2787-2796. [CrossRef]

53. Cox, S.C.; Jamshidi, P.; Grover, L.M.; Mallick, K.K. Preparation and characterisation of nanophase Sr, Mg, and Zn substituted hydroxyapatite by aqueous precipitation. Mater. Sci. Eng. C 2014, 35, 106-114. [CrossRef]

54. Rudko, V.V.; Baran, N.P.; Vorona, I.P.; Ishchenko, S.S.; Okulov, S.M.; Chumakova, L.S. Structure and properties of $\mathrm{CO}_{2}-\mathrm{centers} \mathrm{in}$ biological and synthetic hydroxyapatite. IOP Conf. Ser. Mater. Sci. Eng. 2010, 15, 12032. [CrossRef]

55. Park, J. Hydroxyapatite. In Bioceramics; Springer: New York, NY, USA, 2008; pp. 177-197, ISBN 978-0-387-09545-5. [CrossRef]

56. Lazić, S.; Zec, S.; Miljević, N.; Milonjić, S. The effect of temperature on the properties of hydroxyapatite precipitated from calcium hydroxide and phosphoric acid. Thermochim. Acta 2001, 374, 13-22. [CrossRef]

57. Bertoni, E.; Bigi, A.; Cojazzi, G.; Gandolfi, M.; Panzavolta, S.; Roveri, N. Nanocrystals of magnesium and fluoride substituted hydroxyapatite. J. Inorg. Biochem. 1998, 72, 29-35. [CrossRef]

58. Zyman, Z.; Tkachenko, M.; Epple, M.; Polyakov, M.; Naboka, M. Magnesium-substituted hydroxyapatite ceramics. Materwissenschaft Werksttechnik 2006, 37, 474-477. [CrossRef]

59. Suciu, O.; Ioanovici, T.; Bereteu, L. Mechanical Properties of Hydroxyapatite Doped with Magnesium, Used in Bone Implants. Appl. Mech. Mater. 2013, 430, 222-229. [CrossRef]

60. Vorona, I.P.; Ishchenko, S.S.; Baran, N.P. The effect of thermal treatment on radiation-induced EPR signals in tooth enamel. Radiat. Meas. 2005, 39, 137-141. [CrossRef]

61. Boanini, E.; Gazzano, M.; Bigi, A. Ionic substitutions in calcium phosphates synthesized at low temperature. Acta Biomater. 2010, 6, 1882-1894. [CrossRef] [PubMed]

62. Kis, V.K.; Sulyok, A.; Hegedűs, M.; Kovács, I.; Rózsa, N.; Kovács, Z. Magnesium incorporation into primary dental enamel and its effect on mechanical properties. Acta Biomater. 2021, 120, 104-115. [CrossRef]

63. Ishchenko, S.; Vorona, I.; Baran, N.; Okulov, S.; Nosenko, V. Thermally induced changes of the carbonate structure in biological hydroxyapatite studied by EPR and ENDOR. Ukr. J. Phys. 2009, 54, 231-237.

64. Beshah, K.; Rey, C.; Glimcher, M.J.; Schimizu, M.; Griffin, R.G. Solid state carbon-13 and proton NMR studies of carbonatecontaining calcium phosphates and enamel. J. Solid State Chem. 1990, 84, 71-81. [CrossRef] 